\title{
CREACIÓN DE LA MALLA EN EL CONJUNTO ARQUEOLÓGICO DE CÁSTULO: DE LA DISCIPLINA AL VECTOR
}

\author{
Ma Paz López Rodríguez, Libertad Serrano Lara, David Expósito Mangas. ${ }^{1}$
}

\section{Resumen:}

Desde que, en el año 2011, el proyecto Forvm MMX comenzase a desarrollar su trabajo en el yacimiento ibero-romano de Cástulo, (Linares, Jaén), siempre ha apostado por el uso y aplicación de nuevas tecnologías, empleando un innovador sistema de registro telemático (Imilké) al que se añade el desarrollo de las aplicaciones posibilitadas por el modelado 3D durante las fases sucesivas del proceso de excavación y el estudio de materiales. Este último conforma el objetivo principal del presente artículo.

Mediante las técnicas de fotogrametría, el desarrollo de modelos tridimensionales de cada estrato queda integrado en el sistema permitiendo su acceso de forma virtual, gracias al uso de un SIG. Mientras, las piezas tienen un recorrido por las diferentes etapas que componen el proyecto: conservación, catalogación, modelado, difusión pública y usos didácticos. En el texto desarrollamos este trabajo mediante dos ejemplos concretos, ambos de época romana, seleccionados a partir de las necesidades y aplicaciones empleadas durante la conservación y catalogación.

Se crea así un equipo interdisciplinar que, desde diferentes ámbitos, ofrece resultados abiertos de modo virtual a otros investigadores y/o docentes interesados en el análisis global de toda la documentación generada durante la excavación arqueológica.

\section{Palabras clave:}

arqueología virtual, fotogrametría, catalogación, restauración, Castulo

\section{Abstract:}

Since 2011, when the Forvm MMX project began to undertake work on the Iberian-Roman settlement of Cástulo (Linares, Jaén), we have always endeavored to use and apply new technologies as part of our efforts, using an innovative computer database for recording finds and excavation units (Imilké), as well as developing possibilities for employing 3D modeling throughout various phases of excavation and the study of artifacts. The latter aspect of our work forms the principal subject of the present article.

1 Los autores pertenecen al equipo técnico del proyecto general de investigación Forvm MMX, aprobado por la Consejería de Educación, Cultura y Deporte (Junta de Andalucía) en el Conjunto Arqueológico de Cástulo, Linares. Coordinando, respectivamente, las áreas de investigación arqueológica en: conservación-restauración, Rodríguez López, M.P.; documentación tridimensional, Serrano Lara, L.; y catalogación, Expósito Mangas, D. 
Through the techniques of photogrammetry, we are able to create three-dimensional models of each excavated stratigraphic unit that are integrated into the database using a GIS - thus allowing access to them in a virtual form. Artifacts, on the other hand, travel through various stages as they make their way through the project: conservation, cataloguing, drawing and photography, publication, and didactic use. In this article, we will describe our process using two examples, both of Roman date, which demonstrate the interventions used in conservation and cataloguing.

We have created an interdisciplinary team whose members come from a variety of backgrounds, and whose work offers open results in a virtual format to other researchers and scholars interested in a global analysis of the documentation generated by an archaeological excavation.

\section{Key words:}

virtual archaeology, photogrammetry, cataloguing, restoration, Cástulo

\section{Contexto espacio temporal}

La ciudad ibero-romana de Cástulo, emplazada en la margen derecha del río Guadalimar, constituye uno de los centros capitales del mediodía peninsular durante la antigüedad, tanto por la extensión de su recinto amurallado (50 ha.), como por su posición estratégica en la cabecera del valle del Guadalquivir. La ciudad destaca como nudo principal en las vías de comunicación de la época y, a lo largo de su historia, tuvo un acceso privilegiado a los recursos mineros de Sierra Morena. El oppidum de Cástulo, primero, fue el más importante núcleo de población de la Oretania ibérica y, más tarde, se constituyó en municipio romano, llegando a ser sede episcopal en época bajo-imperial.

Los autores clásicos otorgaron un especial reconocimiento a la ciudad de Cástulo, debido en particular a su protagonismo en el transcurso de la II Guerra Púnica. Cástulo, en un primer momento, destaca por su fidelidad a la causa cartaginesa y acaba suscribiendo una alianza con Roma. Circunstancia que le va a permitir mantener una excepcional autonomía política como manifiesta en esa coyuntura su capacidad para acuñar moneda.

En abril de 2011 se pública en el B.O.J.A. la incoación del expediente de delimitación de la Zona Arqueológica de Cástulo, y en julio, el Decreto de creación del Conjunto Arqueológico de Cástulo. En esa fecha se inician también las actividades del proyecto Forvm $M M X^{2}$, concretadas en una actividad de excavación

2 Un proyecto del Instituto Universitario de Investigación en Arqueología Ibérica (Universidad de Jaén), que promueve el Ayuntamiento de Linares y financia la Consejería de Economía, Innova- 
arqueológica puntual titulada Localización y primera caracterización del foro de la ciudad romana de Cástulo. Ésta fue prorrogada en 2012 y tuvo continuidad en 2013-2014 con otra actividad puntual encaminada a la conservación y adecuación de las áreas excavadas. Dichos ciclos de excavación han servido para saber que en ninguna de las dos áreas excavadas se situaba el foro de la ciudad, pero también, para ilustrar dos lugares del centro monumental de la ciudad romana mediante el hallazgo de sendos edificios relevantes de la arquitectura pública.

Fig. 1.

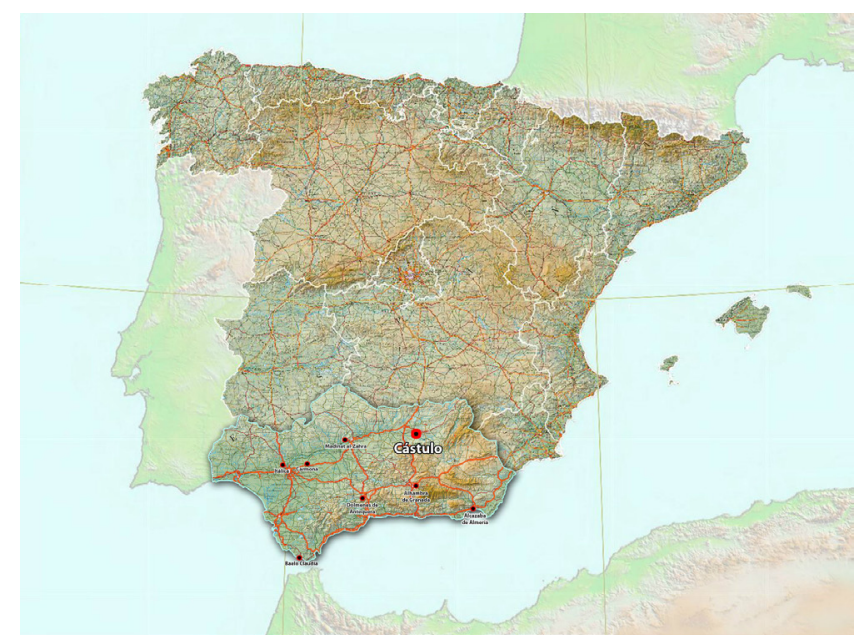

Fig. 2.

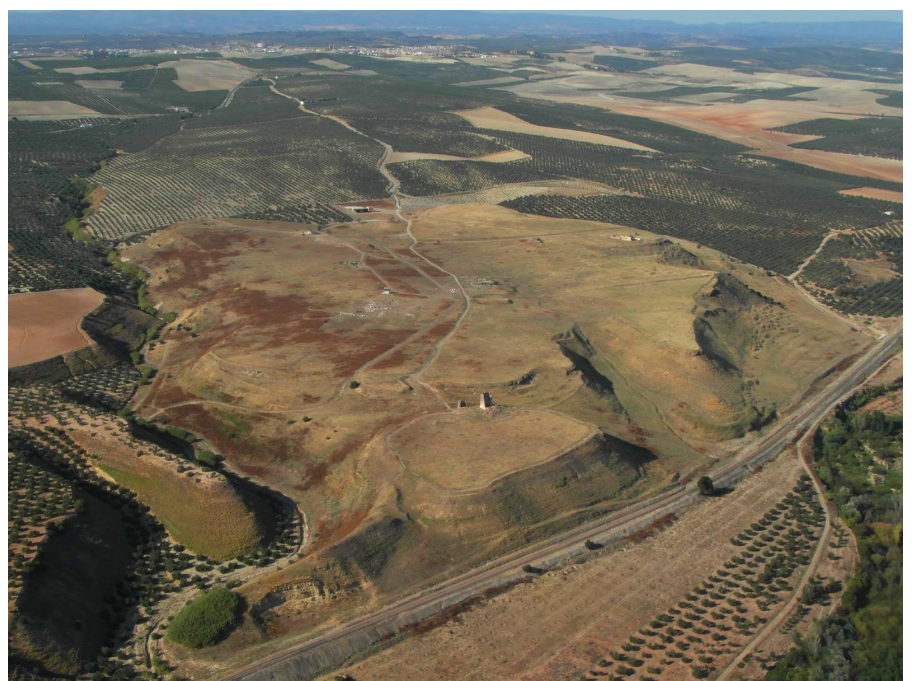

ción, Ciencia y Empleo de la Junta de Andalucía, en el Conjunto Arqueológico de Cástulo (Consejería de Educación, Cultura y Deporte). 
En conjunto, los datos reunidos indican que la ciudad fue objeto de importantes obras públicas a caballo entre los siglos I y II, entre otras las termas y las letrinas hasta ahora conocidas. Segundo, que los niveles correspondientes a buena parte del siglo II y del siglo III aparentemente no existen, evidenciando un colapso en las instituciones políticas y económicas que tuvieron su sede en esa anterior arquitectura pública. $Y$ tercero, que la ciudad resurge de sus cenizas en los siglos IV y V, cuando volvemos a notar una intensa actividad en las dos áreas exploradas.

No parece necesario justificar la necesidad de conocer para revalorizar Cástulo, los esfuerzos hasta ahora realizados ejemplifican el alto valor patrimonial de Cástulo y han proporcionado una idea más precisa del trabajo que aún queda por hacer, pero resultan claramente irrelevantes en comparación con las largas trayectorias investigadoras de los demás conjuntos andaluces.

\section{Documentación digital: la apuesta tecnológica}

El proyecto Forvm MMX ha desarrollado un sistema inédito e innovador para la generación y gestión de documentación arqueológica denominado Imilké. El principal objetivo reside en la posibilidad de traslación inmediata de los datos arqueológicos desde el yacimiento a la base de datos hospedada en un servidor online. Por otro lado, el diseño del sistema de registro permite una optimización del trabajo de campo y supone un método de trabajo estandarizado para todo el Conjunto Arqueológico de Cástulo. Esto permite el trabajo simultáneo de varios equipos de trabajo ya que, con independencia de la cantidad de equipos que estén abiertos, el sistema de registro generará una única documentación.

Las herramientas utilizadas son sencillas: formularios en papel con una impresión de micro-trama que permite al dispositivo reconocer el campo que se está cumplimentando en la base de datos gracias al micro-escáner incluido en un bolígrafo digital (BlackPen). Vía Bluetooth los datos se envían desde el bolígrafo digital a su "Smartphone" y de ahí al servidor a través de la conexión de datos a Internet. Hay 5 campos diferentes dependiendo del tipo de información a registrar, bien sean datos espaciales, información gráfica, descripción de la estratigrafía o inventario de materiales.

No sólo se ha agilizado el proceso de documentación sino que su calidad ha mejorado mediante la obtención de modelos tridimensionales de cada estrato y nivel del mismo. El resultado es la producción de documentos de calidad fotográfica que profundizará en el proceso de investigación-excavación arqueológica virtualmente. "Too Waste 3 asegura el relato sistemático del proceso de excava-

3 Imliké, sistema de registro digital empleado en la documentación arqueológica por el proyecto Forvm MMX, recibió la denominación provisional de TooWaste. 
ción, transfiriendo los datos de campo -en tiempo real- a un ordenador remoto, y obtiene un modelado tridimensional exhaustivo de sedimentos, construcciones y objetos" (CASTRO et alii. 2014:16 ).

La primera unidad definida es el volumen. Mediante el uso de una Estación Total se adjudican sus coordenadas $\mathrm{X}$ e $\mathrm{Y}$, mientras que el nivel queda definido mediante la coordenada Z. Esta unidad distingue y permite definir diferentes tipos de volúmenes como son el nivel superficial, la división por construcción o una división completa, o bien, subjetiva del espacio. Cada unidad estratigráfica y la totalidad del material hallado reciben un código específico del sistema Imilké asociado a dicho volumen. ${ }^{4}$ En los casos de estudio de modelado tridimensional para materiales singulares que vamos a desarrollar haremos referencia al código de registro de cada objeto. Éste permite el acceso al estrato y nivel en el que fueron recuperados así como la posición exacta del volumen al que pertenecen mediante el visor de volúmenes que son integrados en el Sistema de registro mediante un SIG (Sistema de Información Geográfica). De este modo el investigador tiene acceso a la documentación de forma inmediata permitiéndole un análisis de forma global sobre la misma.

Las nuevas posibilidades de modelado 3D están cambiando la forma de interpretar los espacios y objetos arqueológicos, y especialmente, su forma de representación. La documentación tridimensional, generada en la excavación por el proyecto FORVM MMX, también produce documentación gráfica 2D, como los dibujos a escala precisa de los planos de los sondeos y de los perfiles estratigráficos. Esto representa un salto cualitativo a la hora de elaborar la documentación gráfica de la investigación, ya que el método tradicional funciona de forma inversa, generando de reconstrucciones en 3D a partir de los dibujos de la excavación.

Permitir este análisis arqueológico exhaustivo de las piezas halladas en el Conjunto Arqueológico de Cástulo es el objetivo de la virtualización de las mismas, labor desarrollada por el equipo de digitalización. Formando parte de las fichas de catalogación, el modelo tridimensional está insertado en un archivo pdf interactivo, que incluye todos los datos necesarios para la interpretación arqueológica. La aplicación en las actividades de conservación también es clara al suponer una representación mimética del estado en que la pieza apareció en la excavación y su tratamiento inicial, el modelo tridimensional supone un registro documental en caso de que se produjera algún daño posterior sobre la pieza. Ambas ventajas - la preservación y la difusión del patrimonio público - ya han sido priorizados por el proyecto 3D-ICONOS de la Unión Europea, que, a través del proyecto Carare y

4 El registro de objetos arqueológicos queda dividido en tridimensionales o individualizados. Los registros tridimensionales están espacialmente referenciados al volumen que los contiene, al campo específico del tipo de material y su tratamiento. También es posible añadir imágenes de datos, proceso y / o resultados. La forma de registros individuales contiene la misma información que los registros tridimensionales, con la diferencia de que en este campo la posición exacta queda registrada mediante la asignación de las coordenadas X, Y, y Z permitiendo ser reproducidas posteriormente. 
la plataforma Europeana ${ }^{5}$, fomenta la creación de proyectos para la virtualización del patrimonio arqueológico.

Partiendo de la base de este apoyo interdisciplinar el equipo de representación gráfica consulta con los de catalogación y la información extraída de cada pieza antes de comenzar a crear el levantamiento fotogramétrico que originará la malla vectorizada de los objetos arqueológicos. La apuesta por el empleo de modelos 3D como herramienta de análisis y estudio en las fases sucesivas del proceso de excavación y el estudio de materiales debe implicar una garantía de autenticidad y fidelidad que impiden la edición de la malla o el añadido de elementos a la misma. Estos modelos fotogramétricos reproducen la totalidad de la pieza sin ediciones que disimulen huecos en la geometría del objeto o mejoren la resolución el mapa de texturas.

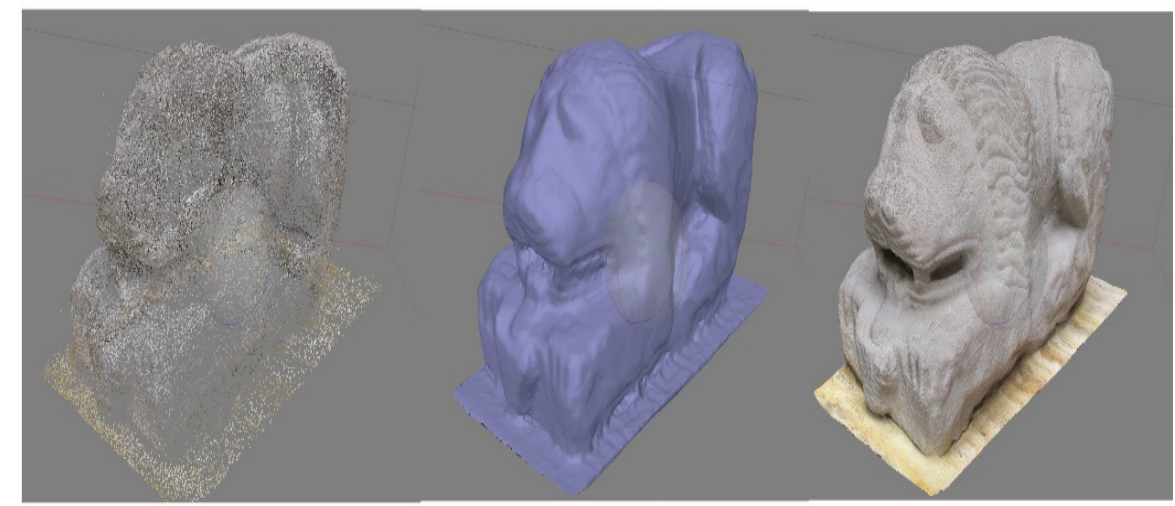

Fig. 3. Modelo tridimensional de la escultura "León ibero-romano", Museo Arqueológico de Linares. Toma de datos fotográficos y levantamiento fotogramétrico: Libertad Serrano Lara)

Serán los técnicos de conservación y catalogación quienes junto al equipo de representación gráfica decidan las posibilidades de análisis, reconstrucción, restitución o anastilosis virtual que ofrecen las piezas. Planteándose los posibles estudios lumínicos sobre la pieza, con el fin de obtener mejor análisis de algunos detalles, y las posibles escenografías que permitan el estudio o comprobación de la hipótesis de funcionalidad interpretada para las mismas. También durante esta fase se siguen respetando los principios de autenticidad y rigurosidad histórica ${ }^{6}$

5 La comisión Europea realizó la recomendación 27.10.2011 a todos sus miembros en la que se incluían algunos objetivos y consejos de empleo para la digitalización y conservación del patrimonio cultural. Se promovió la creación de más de 30 millones de objetos digitalizados, incluyendo las grandes obras maestras de Europa que ya no poseen derechos de autor. Accesible en: http:// www.europeana.eu/portal/.

6 Tanto en los "Principios de Sevilla" como en la "Carta de Londres" las recomendaciones para la 
mientras da comienzo el planteamiento de los últimos pasos en el recorrido de los modelos tridimensionales dentro del proyecto Forvm MMX, la difusión pública y el empleo didáctico.
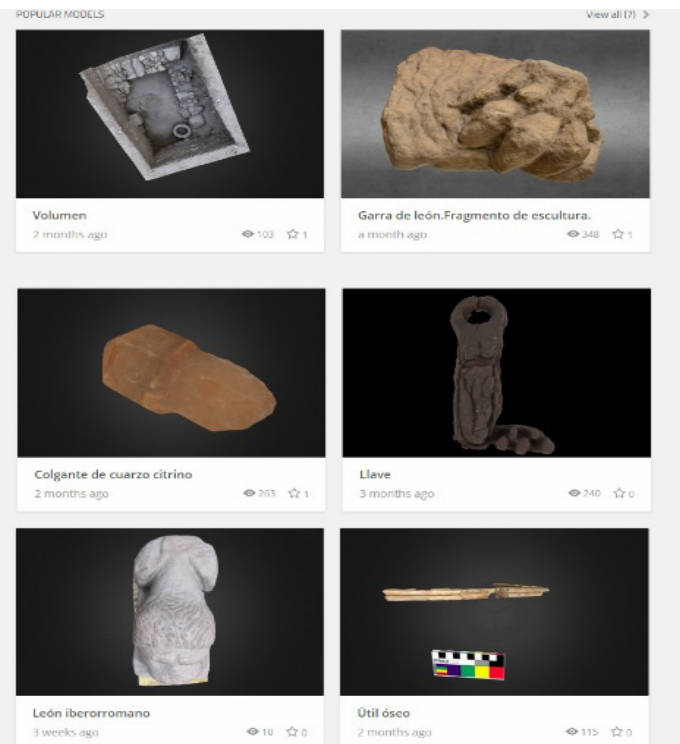

Q 10 占识

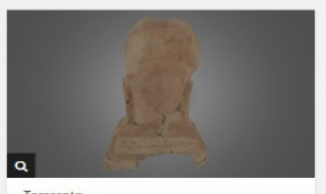

Util óseo
zmonths age
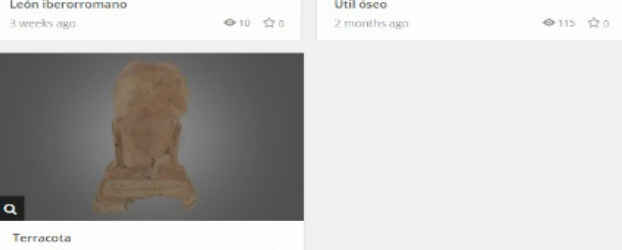

Terracota

Fig..4. (Modelos 3D de elementos arqueológicos publicados en acceso abierto por FORVM MMX).

Actualmente asistimos a un interesante y enriquecedor debate acerca del empleo de modelos 3D obtenidos mediante levantamiento fotogramétrico en la difusión pública del patrimonio arqueológico, más allá de los límites que sean necesarios según el tipo de público para el que se plantea la aplicación virtual en la que se incluirá el objeto tridimensional. Esta discusión acabará lógicamente derivando en la necesidad de crear unos parámetros sobre los metadatos que deberán anexionarse a los mismos, así debe quedar constancia no sólo sobre el

creación y empleo del Patrimonio Cultural virtualizado apuntan las posibilidades que éste ofrecen en actividades de difusión pública basadas en fines de "espectacularidad" que pueden Ilegar a contradecir el sentido de investigación y la necesaria rigurosidad científica en un registro digital de elementos arqueológicos. Accesibles en :http://www.arqueologiavirtual.com/carta/wp-content/ uploads/2012/03/BORRADOR-FINAL-FINAL-DRAFT.pdfY en: http://www.londoncharter.org/fileadmin/templates/main/docs/london charter 21 es.pdf 
proceso de creación, fechas, software empleado, número de puntos en la nube densa, polígonos de la geometría o resolución del mapa de texturas, sino el propio material resultante de la toma de datos que lo genera, es decir, los archivos fotográficos RAW. ${ }^{7}$ De este modo permitimos que vuelvan a generarse nuevos modelos 3D cuando pueda accederse, y ocurre con celeridad, a nuevos software que actualicen y mejoren los resultados. De algún modo se reivindica el carácter flexible que las herramientas tecnológicas aportan a la interpretación arqueológica y la reversibilidad en la restauración virtual.

En cualquier caso nuestro planteamiento en los trabajos de difusión pública es el de crear una nueva experiencia (virtual) que permita el acercamiento a la antigua ciudad de Cástulo a través de los objetos arqueológicos en ella hallados. Puede que de un modo más participativo gracias a las plataformas online Sketchfab o Youtube pero nunca con la intención de sustituir la exposición real de las piezas. ${ }^{8}$

A continuación ofrecemos una tabla sobre las aplicaciones al estudio arqueológico y los trabajos de difusión realizados con cada pieza objeto de estudio incluida en este artículo, así como los enlaces actuales en la plataforma web donde han sido publicados.

\begin{tabular}{|l|l|l|}
\hline $\begin{array}{l}\text { Autores del modelo 3D.Objeto y códi- } \\
\text { go de registro en Toowaste. }\end{array}$ & \multicolumn{2}{|c|}{ Aplicación al estudio y difusión. } \\
\hline $\begin{array}{l}\text { Fotografía: J.M. Pedrosa Fotogrametría } \\
\text { y renderizado: L. Serrano }\end{array}$ & - Anastilosis virtual & $\frac{\underline{\text { https://www.youtu- }}}{\frac{\text { be.com/watch? }=\mathrm{LA}-}{\text { cAi_nebw2k }}}$ \\
\end{tabular}

7 Sobre este aspecto reflexionan varios autores en la obra colectiva "Vision of Substance" editada por la Universidad de Dakota Norte donde se proponen una serie de principios para el diseño de las bases de datos de los modelos tridimensionales arqueológicos. Accesible en:https://mediterraneanworld.wordpress.com/2015/01/19/visions-of-substance-3d-imaging-in-mediterranean-archaeology-the-book/

8 "A good surrogate is not merely a copy: it is supposed to provide, in some sense, access to the original, now made ubiquitous and opened for inspection on a level of detail that the original itself might not allow". A.RABINOWITZ. Vision of Substance. 3D Imaginig in Mediterranean Archaeology. The University of Dakota, 2015. Pág. 29 


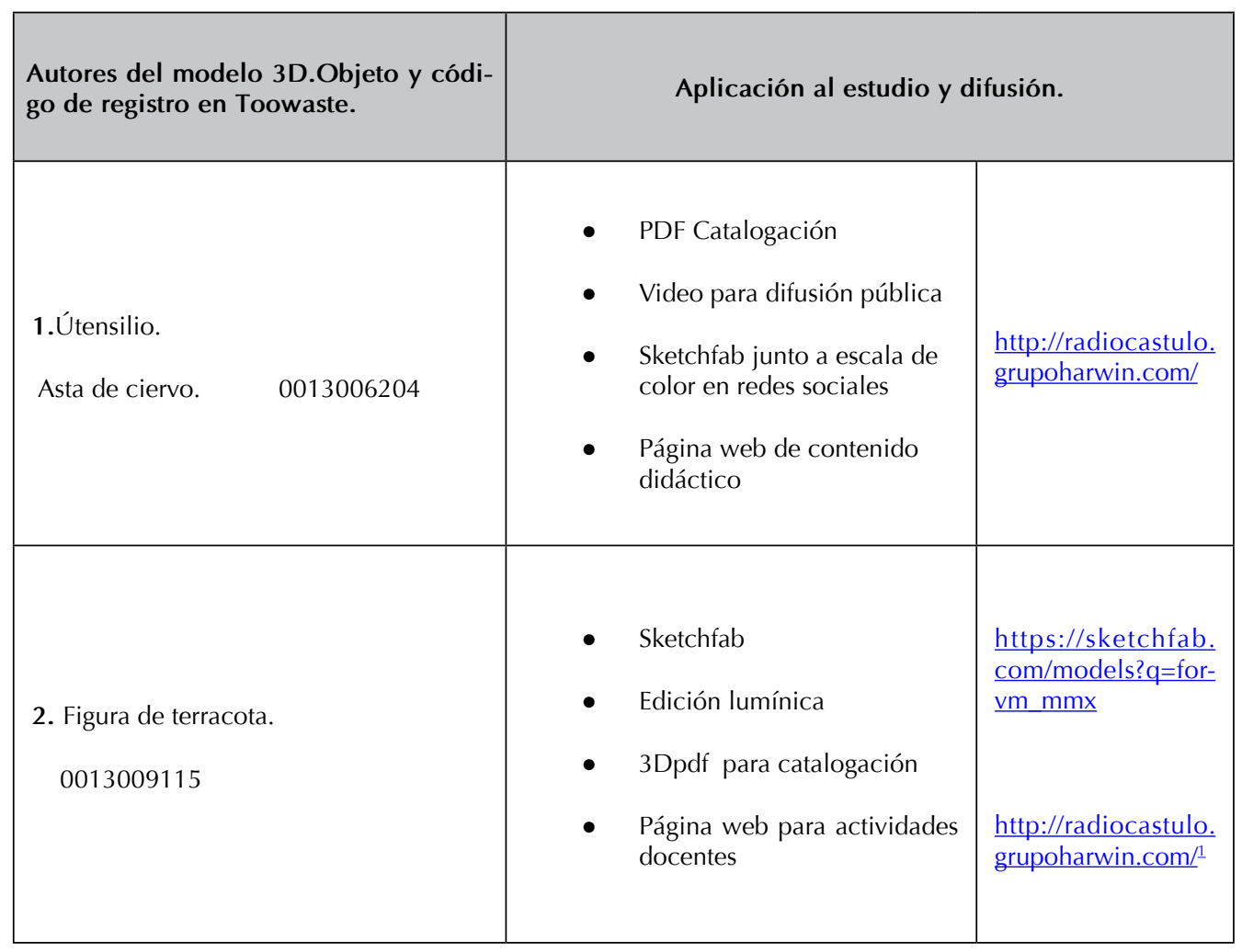

\section{Casos de estudio, levantamiento fotogramétrico aplicados al estudio de catalogación y restauración arqueológica}

Para la participación en este encuentro y a modo ejemplificativo elegimos dos casos significativos de artefactos elementos materiales hallados durante la campaña de excavación de 2013 llevada a cabo por el proyecto Forvm MMX.

El levantamiento fotogramétrico de los mismos supuso en ambos casos un verdadero ejercicio de trabajo en equipo.

En primer lugar, hacemos referencia a una pieza elaborada en terracota, consignada con la sigla 0013009115.

En segundo lugar, una pieza elaborada en soporte óseo, consignada con el número de registro 0013006204, que fue recuperada en varios fragmentos y, dada su fragilidad, conlleva un dilatado proceso de restauración, labor que también es descrita con detalle en este artículo. 


\section{Figura de terracota portante de instrumento musical, sigla 00130009115}

Localizada durante la campaña 2013 en el área 2 del yacimiento de Cástulo, el objeto apareció en un nivel de tapiales muy erosionados, correspondiente a la última fase tardorromana del yacimiento, fechada entre los siglos IV-V d.C. La pieza se corresponde con una figura humana, de apenas medio kilo de peso, elaborada mediante molde univalvo. La terracota representa a una figura sedente, entronizada, vestida con túnica corta, y que porta entre sus manos un artefacto, que en un primer momento presentó, por su singularidad, algunos problemas de identificación. La restauración efectuada permitió reintegrar casi la totalidad de la pieza, a excepción de la cabeza. Dicho proceso contribuyó a acrecentar el conocimiento inicial, y facilitó la identificación de muchos de los detalles propios de la figura, como la posición de sus miembros, el tipo de asiento, el podio sobre el que reposan sus pies, el tipo de vestimenta, etc.

El primer paso para el levantamiento fotogramétrico es la toma de datos, realizada con un objetivo MicroNikor, distancia focal de $60 \mathrm{~mm}$ y un diafragma (2232). El principal reto en esta pieza consistió en procurar un número y tipo de tomas que permitiera observar el interior de la pieza tanto desde la base como en la zona de fractura localizada en el cuello de la figura, puesto que no conservaba la cabeza. Con un total de 75 imágenes se obtuvo una nube densa de 5.953 .746 puntos mediante la elección de una resolución alta en la generación de la malla (90.000 polígonos) ofrecida por el programa empleado, Agisoft Photoscan. ${ }^{9}$ La geometría final del modelo poligonal presenta 595.680 vértices y 1.190 .748 caras, lo que permitió una magnífica calidad en el posterior proceso de obtención del mapa de texturas que permite el visualizado y análisis a los compañeros de catalogación.
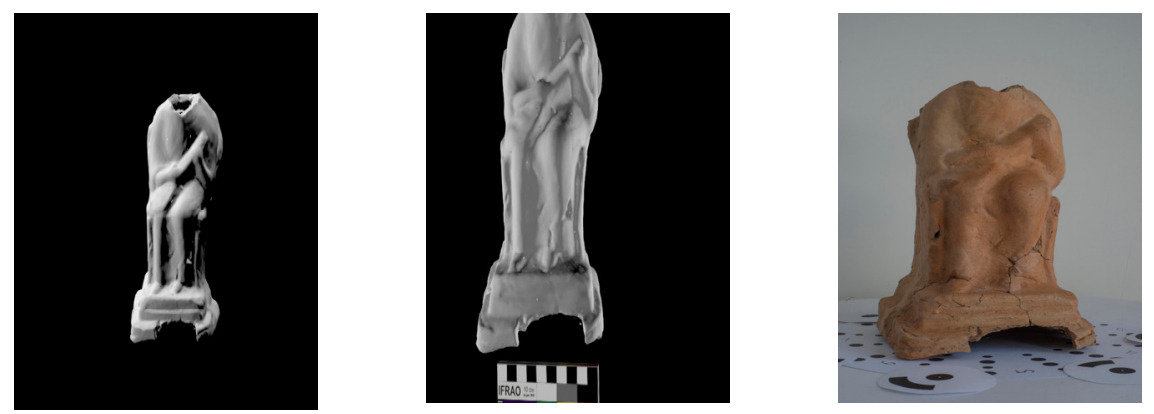

Fig. 5,6 y 7. Edición lumínica y renderizados mediante Blender sobre el modelo tridimensional de la figura de terracota con código de registro, 00130009115 . Fotografía empleada en la generación del modelo fotogramétrico).

9 La resolución de la malla y de la textura es editable por el usuario, permitiendo un número mayor que el considerado alto por el software de levantamiento fotogramétrico empleado, en este caso, ante la calidad del modelo final obtenido no fue necesario aumentarlo. 
En este punto consideramos que mediante la virtualización de la figura se podrían identificar otros aspectos más complicados de esclarecer a simple vista. Para llevar a cabo la aplicación de varios filtros, así como la realización de diferentes pruebas lumínicas, convertimos el archivo a un objeto importable en el programa de dibujo asistido Blender. Una vez asignadas las coordenadas virtuales, pudimos proyectar sobre la pieza haces de luz desde varias posiciones que contribuyeron a identificar, finalmente, el objeto que la figura portaba entre sus manos.

En efecto, el objeto que sujeta la figura representa un instrumento musical de cuerda, con mástil y caja de resonancia. La bibliografía, no excesivamente profusa en este caso, si hacía referencia a la existencia de un instrumento musical, conocido como pandoura o pandura, el antepasado de la guitarra actual. Conocido desde tiempos remotos, con algunos ejemplos primigenios en Mesopotamia, Ilega al mundo clásico a partir del siglo IV a.C., desde donde se difunde por todo el Mediterráneo, teniendo constancia de su presencia en la Península Ibérica, aunque con algunas dudas, antes de la llegada de Roma. (ROMÁN RAMíREZ. 2011)

Las labores de digitalización de la pieza y el análisis virtual de la misma también contribuyeron al estudio de la gestualidad de la figura, pudiéndose establecer, incluso, que la posición de las manos indicaba una actitud o pose directamente ligada con el tañido del instrumento.

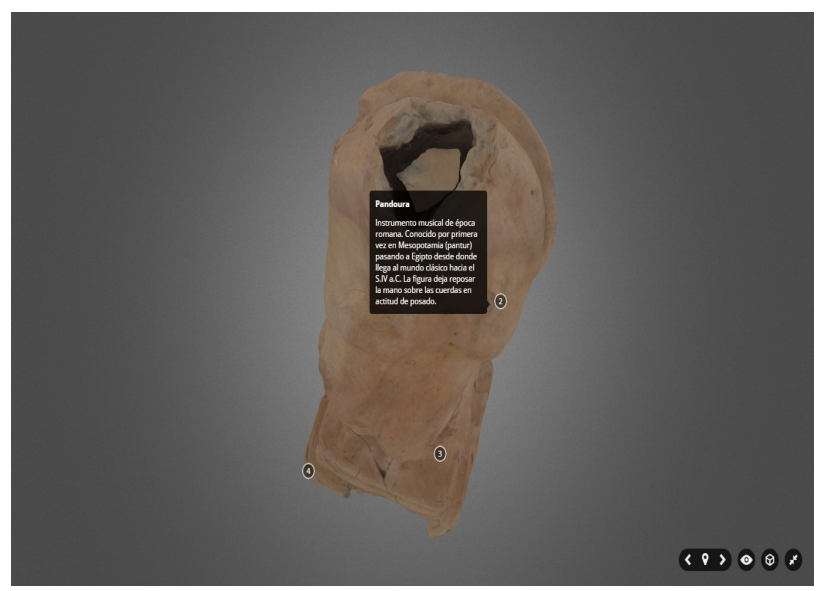

Fig. 8. Anotaciones de carácter divulgativo para la publicación del elemento singular, con código de registro 00130009115, como modelo 3D).

A pesar de encontrarnos ante una disciplina muy extendida en la sociedad romana, momento en el que se elabora la pieza, el registro arqueológico ligado a la coroplastia no nos ha aportado, hasta la fecha, muchos ejemplos próximos a la pieza en cuestión. Sin embargo, sí encontramos referencias más precisas en el campo de la escultura. Así, contamos con la existencia de bajorrelieves alusivos a 
instrumentos musicales similares en sarcófagos conservados en el British Museum de Londres o el Museo Arqueológico de Arlés, en Francia, por citar algunos de los más conocidos. Sin lugar a dudas uno de los ejemplos más próximos lo conforma una estela conservada en el Museo Nacional de Arte Romano de Mérida. Dicha inscripción funeraria presenta un campo figurativo por encima del texto, en el que se representa a la difunta, una joven, Lutatia Lupata, que aparece tocando un instrumento de cuerda con mástil, muy similar al representado en la terracota. (GARCÍA Y BELLIDO. 1957:233-244)

Por la originalidad y carácter excepcional que supuso el análisis formal de la obra se consideró interesante para un amplio público el acceso directo a su modelo tridimensional y, de este modo, a una síntesis del estudio de catalogación que permitía compartir de un modo más completo el hallazgo. Es preciso mencionar que el grado de interés de los propios ciudadanos de la ciudad de Linares y municipios circundantes es muy alto, parejo a su grado de implicación directa en labores de voluntariado dentro del propio Conjunto Arqueológico de Cástulo. De ahí la pretensión de su publicación en diferentes redes sociales, aportando información científica a la altura de las expectativas y resultando amena al mismo tiempo, con el fin de despertar el interés del público que, en general, disfruta el Patrimonio Cultural.

\section{Utensilio óseo, sigla 0013006204}

Exhumado durante la campaña 2013 sobre el suelo de una habitación cuya ocupación, gracias al análisis de la cerámica, el repertorio numismático y los elementos metálicos que completaban el conjunto, fue fechada entre finales del siglo IV y la primera mitad del siglo V d.C. En la actualidad se barajan varias hipótesis acerca de la funcionalidad de esta estancia, aún no excavada en su totalidad, y que forma parte de un gran complejo de época tardorromana. El utensilio se encuentra realizado sobre asta de ciervo, concretamente, sobre una de las luchaderas o puntas iniciales de la osamenta de este animal. El proceso de pulido que se observaba, así como la decoración conservada, Ilamaron poderosamente la atención al equipo, puesto que, dentro del registro arqueológico recuperado, no teníamos hasta el momento una pieza similar.

Esta pieza, fue exhumada en varios fragmentos y, dada su fragilidad, supuso un dilatado proceso de restauración. La propia composición química y las características físicas del hueso, su deleznabilidad, higroscopicidad y porosidad, confieren al material óseo arqueológico una gran debilidad; la mayoría de las propiedades y factores de composición del suelo y los procesos de sedimentación condicionan de manera grave su estado de conservación que provocan daños como los que presentaba este caso. Se encontraron agrupados 12 fragmentos de lo que 
parecía un objeto de hueso decorado con incisiones. Su ubicación, color, forma, decoración y parecidas formas de alteración nos hicieron pensar que pertenecían a una misma pieza y fueron tratados en conjunto. Los diferentes fragmentos encontrados, tras una cuidadosa extracción fueron depositados en un recipiente plástico hermético al que se le introdujo un hisopo de algodón humedecido para conservar una humedad relativa alta en su interior.

La pieza presentaba un mal estado de conservación y una grave debilidad estructural. Estaba incompleta, parecía conservar menos del $50 \%$ del total. Se encontraba poco consistente, presentando sequedad, fisuras y grietas, pérdidas de material en capas superficiales dejando huellas de cavernillas, concreciones de carbonato cálcico puntuales poco adheridas y depósitos de tierra superficiales.
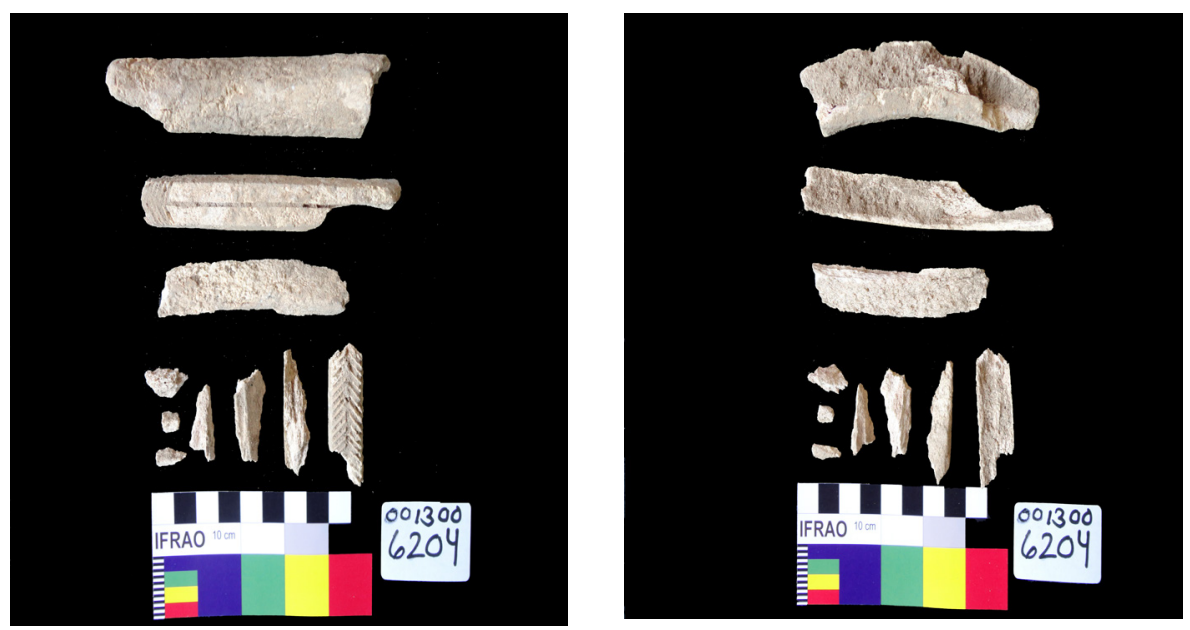

Fig. .9(1) y 9(2). Estado inicial de una parte del útil óseo).

Una vez diagnosticadas las patologías de la pieza se estableció el tratamiento de conservación necesario, respetando en todo momento la pieza original dentro de los parámetros de reversibilidad e intervención mínima. En este sentido en el tratamiento del objeto se centró en la limpieza mecánica de las tierras y carbonataciones bajo la lupa binocular. Y sobre todo, en solucionar la falta de consolidación a base de inmersiones de los fragmentos en una disolución de resina acrílica en acetona.

Del total de doce fragmentos pudieron unirse todos entre si menos uno que por textura, color, fractura se pudo situar de manera bastante acertada aunque se decidió no colocarlo pues la pérdida de material lo hacía imposible sin una reintegración volumétrica. Los restantes presentan unos puntos de unión con una superficie de adhesión escasa para asegurar un buen agarre entre unos y otros por lo que hubiera resultado una composición inestable. Por esta razón hubiera sido un paso ineludible la reintegración volumétrica y de color si se hubiese optado por esta vía. 
Para esta pieza de hueso en cuestión, sustentado por uno de los criterios fundamentales de la conservación que es la mínima actuación, se opta por la restauración real y virtual valiéndonos del modelado digital en 3D. Este sistema ha ayudado a solventar los problemas de montaje que hubiera supuesto una agresiva reintegración volumétrica, permitiendo, al mismo tiempo, el seguimiento de las modificaciones sobre la pieza. ${ }^{10}$

\section{Anastilosis virtual de los tres fragmentos óseos y estudio de catalogación sobre el conjunto virtualizado}

Lo más importante durante la toma de datos fotográficos que permite el procesos automático - obtención de puntos homólogos previa a la generación de la nube de puntos densa- era evitar los problemas derivados de la profundidad de campo necesaria para fotografiar unas piezas de forma alargada y pequeño tamaño. Tanto para la geometría poligonal como para el mapa de texturas es imprescindible la nitidez absoluta en el conjunto total de la pieza fotografiada. Para ello se empleó un objetivo de $60 \mathrm{~mm}$ micro-nikkor que permite un diafragma cerrado en el rango de f/ 42 ó 36. A continuación presentamos los datos básicos obtenidos en el levantamiento fotogramétrico de cada pieza que nos permitirá realizar comparaciones sobre el modelo final, en el que reconstruimos la forma original del utensilio, mediante la unión virtual de los tres fragmentos.

\begin{tabular}{l|l|l|l|l|l|l}
\cline { 2 - 7 } & $\begin{array}{c}\text { Tamaño de } \\
\text { pixel }\end{array}$ & $\begin{array}{c}\mathrm{N}^{\circ} \text { de imá- } \\
\text { genes }\end{array}$ & $\begin{array}{c}\text { Resolución } \\
\text { en malla }\end{array}$ & $\begin{array}{c}\text { Resolución } \\
\text { en textura }\end{array}$ & $\begin{array}{c}\text { No Puntos: nube } \\
\text { densa }\end{array}$ & $\begin{array}{c}\text { No Caras: } \\
\text { malla }\end{array}$ \\
\hline $\begin{array}{l}\text { Fragmento } \\
\text { oseo I }\end{array}$ & $104 \mathrm{M}$ & 40 & 90.000 & 4096 & 109.214 & 17.875 \\
\hline Fragm. II & $104 \mathrm{M}$ & 76 & 90.000 & 4096 & 342.125 & 50.002 \\
\hline Fragm. III & $104 \mathrm{M}$ & 90 & 90.000 & 4096 & 771.728 & 50.010 \\
\hline
\end{tabular}

El objetivo era conseguir la reintegración de la pieza que permitiera aproximarnos a la forma, especialmente su curvatura, y tamaño que el objeto presentaba durante su "vida útil". Para ello exportamos los tres modelos tridimensionales a un tipo de archivo importable a 3DMax - archivo obj - que respeta y conserva sus mapas de texturas. El resultado sería compartido con el compañero de catalogación, pretendiendo facilitar las labores de análisis morfológico previo a la

10 Aportaciones todas ellas beneficiosas para la restauración siempre y cuando se haga un buen uso de estas N.N.T.T. que deben servir como un medio no como un fin, nunca sustituir al objetivo último que es la conservación y exposición de las piezas, sino complementarlo. J.M. TEJADO SEBASTIÁN, J.M. "El escaneado en 3D y prototipo de piezas arqueológicas: Las nuevas tecnologías en el registro, conservación y difusión del patrimonio arqueológico" en IBERIA, nº 8, 2005, p.p. 135-158. 
creación de su ficha genérica. ${ }^{11}$ La elaboración de esta ficha, desarrollada por el propio proyecto Forvm MMX, se adecúa en gran parte a los campos preestablecidos en la base de datos digital DOMUS ${ }^{12}$ a la cual se exporta la información. Y es en ella dónde basamos la información que pretendemos transmitir, de forma didáctica, en las labores de difusión pública para las piezas singulares digitalizadas.

A través de la la anastilosis virtual, permitida por la reintegración efectuada en su restauración, se presenta una primera imagen aproximativa del objeto, del que se conserva aproximadamente $20 \mathrm{~cm}$., casi la totalidad del mismo en origen.

Fig. 10. Renderizado para la anastilosis virtual de los diferentes fragmentos con código de registro 0013006204).

11 Este análisis recopila todos los datos posibles acerca del elemento, partiendo lógicamente de una definición arqueométrica y morfológica, hasta un análisis tipológico. Ambos aspectos son esenciales para la elaboración de una cronología particular y general, además de la propia contextualización del elemento, tanto dentro del yacimiento como en el propio conjunto próximo al hallazgo, indicando la relación existente del mismo con otros materiales próximos y en su mismo locus espacio-temporal.

12 Accesible en:http://www1.ccd.juntaandalucia.es/culturaydeporte/WEBDomus/domus.do?lng=es\&musid=12 
La curvatura, propia del soporte en el que fue elaborado, así como el trabajo de biselado, pulido y elaboración de elementos decorativos (con incisiones de espigas o chevrones), nos pusieron sobre la pista de piezas similares, relacionadas con la actividad textil, hecho que, obviamente, tuvo y ha tenido siempre una especial importancia dentro de la vida doméstica. La pieza fue utilizada presumiblemente como punzón de tejedor (poinçon de tisserand, picker-cum-beater), elemento que servía para aliviar la tensión existente entre la trama y la urdimbre del telar, favoreciendo de esta manera el hilado y confección de tejidos. Su decoración es principalmente funcional: evitar su deslizamiento entre los hilos durante todo el proceso, favoreciendo así su fijación.(GUTIÉRREZ CUENCA. 2010:261-268).

De estos instrumentos textiles contamos con abundantes paralelos, siendo una pieza relativamente habitual y con una morfología genérica, sin apenas variaciones sustanciales desde época prerromana a la Edad Media. Como bien es sabido, tanto el proceso de hilado como la manufactura textil, íntimamente ligados a la vida cotidiana doméstica, son de los aspectos mejor representados dentro del registro arqueológico de muchos yacimientos. Con respecto al soporte y materia prima utilizado, la industria ósea hunde sus raíces en tiempos paleolíticos, por lo que estamos hablando, en ambos casos, de un espectro social ciertamente cercano y con amplia representación.
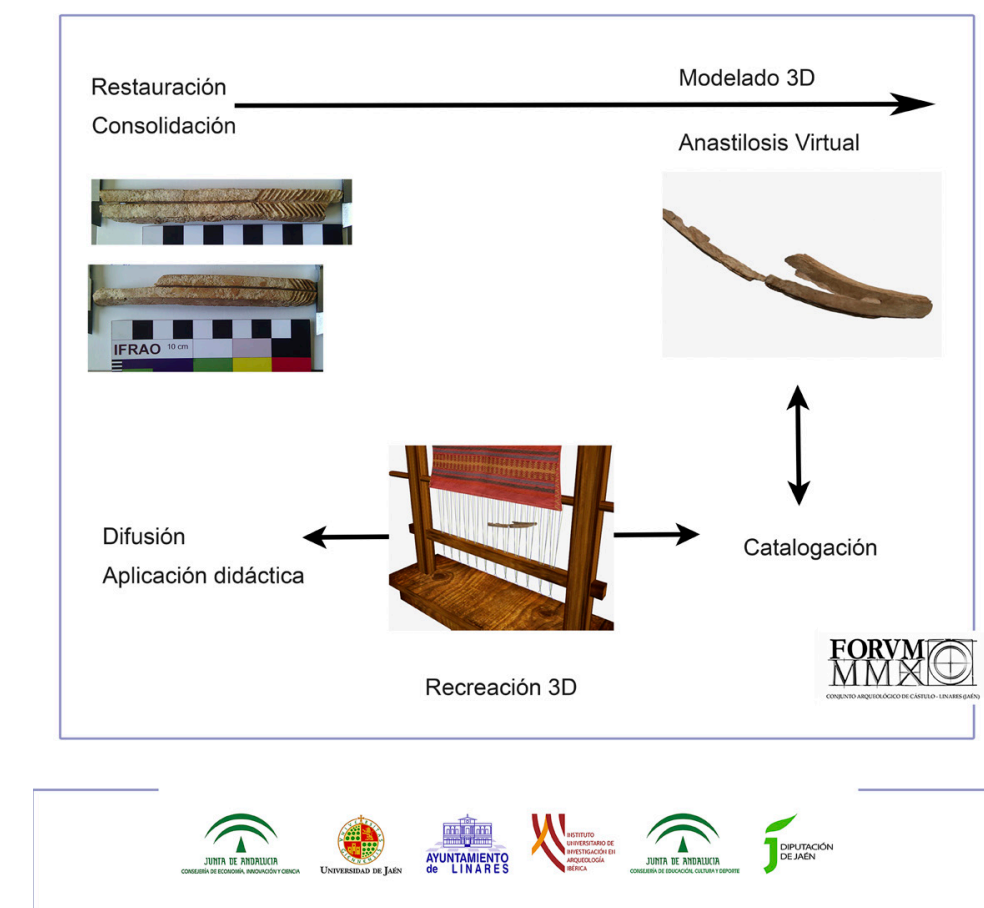

Fig.11. Diagrama sobre el recorrido interdisciplinar del punzón de telar. 


\section{Difusión pública mediante Arqueología Virtual}

Atendiendo a las diferentes hipótesis funcionales propuestas en la ficha de catalogación comenzamos a plantear su adaptación a la difusión pública. Contemplamos las características de la pieza en si, que por su estética resultaba una pieza original y novedosa dentro del conjunto de elementos arqueológicos singulares hasta entonces compartidos con el público mediante plataformas web. Nos interesaba mostrar el proceso de reconstrucción virtual tanto como crear un contexto escenográfico que permitiera comprender su función como punzón de tejedor. Creamos dos clips de vídeo en renderizados de 3DMax como fotogramas individuales en archivos jpg, el primer clip permitía observar los puntos de unión de los tres fragmentos individuales y su restitución final. El segundo, mediante el modelado de un telar con fusayolas, permite recrear la posición que la pieza ocupaba entre la trama del mismo. En última instancia, el dibujo clásico arqueológico ${ }^{13}$ de un paralelo coetáneo confiere el carácter didáctico para el contenido del audiovisual, que al igual que nuestra filosofía de trabajo en equipo, conserva el respeto y aplicación de la representación gráfica clásica como una herramienta insustituible en el estudio y puesta en valor del Patrimonio Arqueológico.

\section{Conclusiones}

Valorar los resultados de la restauración de la pieza con anterioridad a la intervención de la misma, o poder enfrentar diferentes soluciones para futuros tratamientos de restauración, son opciones que se generan con la visualización digital de los artefactos arqueológicos. En el aspecto de la difusión pública las aplicaciones de la Arqueología Virtual ofrece iguales ventajas de rapidez y precisión documental que en el estudio arqueológico. La responsabilidad de no considerar estas herramientas cómo definitivas ayudará a re::estudiar en futuros programas informáticos la figura de un músico realizada en terracota y el utensilio óseo que en un espacio de producción tardoantigua comenzaron a tejer su Historia desde la antigua ciudad de Cástulo.

13 Se emplea el dibujo esquemático sobre el uso de un punzón de telar publicado en 1988 por Cuisinier y Guadagnin en "Un village au temps de Charlemagne. Moines et paysans de l'abbaye de Saint-Denis du VIle siecle a I'an mil." Reunion des Mussés Nationaux. Concretamente, la versión del mismo editada por Gutiérrez Cuenca. 


\section{Bibliografía}

J.M. BLÁZQUEZ. "Cástulo I y II: Excavaciones Arqueológicas en España." Madrid, 1975

M. CASTRO et alii. "El sistema TooWaste, ver. 0 Tecnologías para la traslación arqueológica de las historias en la tierra".Cástulo en Movimiento. Primer avance del proyecto FORVM MMX. Revista 7 Esquinas. Vol. 6. Mayo. Linares, 2014. Pp.16

A. D'ANDREA, F. NICCOLUCCI, K. FERNIE . "3D ICONS metadata schema for 3D objects." Newsletter di Archeologia CISA, Vol. 4. 2013. Pp. 159-181

F. ESCRIBA ESTEBAN Y J.A. MADRID GARCÍA "El mundo virtual en la restauración. Aplicaciones virtuales para la Conservación Restauración del Patrimonio". ARCHE. Publicación del Instituto universitario de restauración de Patrimonio de la UPV, No 4 y 5.2010

A. GARCÍA Y BELLIDO. "Viaje arqueológico por Extremadura y Andalucía". Archivo Español de Arqueología, Vol. 30.Madrid, 1957. Pp. 233-244

E. GUTIÉRREZ CUENCA Y J.A. HIERRO GÁRATE. "Instrumentos relacionados con la actividad textil de época tardoantigua y altomedieval en Cantabria". Munibe Antropología-Arqueología. Vol. 61. San Sebastián, 2010 Pp. 261-288.

J.L. KIMBALL 3D Delineation. A modernisation of drawing methodology for field archaeology. Master's Thesis in Archaeology Department of Archaeology \& Ancient History Lund University, 2014.

C. PAPADOPOULOS, E. PALIOU, A. CHRYSANTHI, E. KOTOULA." Research in the Digital" Age Proceedings of the 1st Conference on Computer Applications and Quantitative Methods in Archaeology Greek Chapter (CAA-GR) Rétino, Creta, 2014.

A. ROMÁN RAMíREZ La música en la Iberia Antigua. De Tartessos a Hispania. Granada, 2011.

J. M. TEJADO SEBASTIÁN, J.M. "El escaneado en 3D y prototipo de piezas arqueológicas: Las nuevas tecnologías en el registro, conservación y difusión del patrimonio arqueológico" . IBERIA, no 8, 2005. Pp. 135-158.

A.RABINOWITZ et alii "Vision of Substance. 3D Imaginig in Mediterranean Archaeology." University of Dakota. 2015.

Nota: Último acceso a todos los enlaces en Abril de 2015. 